\title{
Reliability Analysis of Flanged RC Beams in Limit State of Cracking
}

\author{
Dr.K. Manjunath and R. Meghana Bharadwaj
}

\begin{abstract}
With a view to characterize randomness in the surface crack width of RC flanged beam, an attempt has been made to establish the probability distribution. IS 456-2000 demonstrates the concept of characteristic value for material strength and loads. But the same concept has not been extended to crack width of RC members, even though it is a well known fact that the crack width is a random variable. Since the cracking of a RC members is a highly random process and hence it is not possible to predict the crack width without associating such prediction with some probability of being exceeded. This necessitates the probability modeling of crack width. The concept of characteristic crack width can be formulated only after establishing the probability distribution the crack width follows. For example if the crack width follows a normal distribution then the characteristic crack width is given by, $W_{c h}=W_{\text {avg }}+1.645 \sigma$ Where, $\sigma$ is the standard deviation of crack width. This characteristic crack width has a probability of 5\% of being exceeded. The statistical parameters of crack width like mean and standard deviation are required. In the above equation, a constant 1.645 holds good only for a normal distribution.
\end{abstract}

A very large number of samples are needed for the purpose of computing the statistics of crack width. However to obtain such a large body of statistics a large scale experimentation is to be planned at an exorbitant cost. Digital simulation will solve this problem as it corresponds to artificial experimentation on a computer.

IS 456-2000 has suggested an equation for computing the surface crack width. This equation identifies several basic parameters which influence the crack width. The statistics of these basic variables are taken from the literature. Monte Carlo simulation technique is adopted and sample values of the surface crack width for a beam of known dimensions are generated. The generated values are statistically analyzed and probabilistically modeled. Using the facility on MATLAB platform a suitable probability distribution is tried to describe the randomness in the generated data. Both singly reinforced and doubly reinforced T-Beams are considered for the study. Formulations are made for different location of neutral axis.

The effect of changing each of the basic parameters is studied. The corresponding statistics, probability distribution fitting and histograms are presented. Once the probability distribution is identified, the characteristic value of the crack width is computed at a known level of probability of being exceeded. The characteristic crack width represents the most probable average crack width.

Keywords--- Reliability Analysis, Flanged Beam, Monte-Carlo Simulation, Histogram, Probability Distribution Curve

\section{A. Characterization}

\section{INTRODUCTION}

Characterization is the process of establishing the statistics of a random variable. This randomness is characterized by different probability distribution function. To generate the sample of random variable numerical simulation methods are used and probability modeling is done. After knowing the distribution which the random variable follows representative values like characteristic value which has the probability of exceedence can be defined.

IS 456-2000 considers the characteristic values as that value which has $5 \%$ of being exceeded or being lowered. With the advent of fast digital computers generation of random variables by numerical simulation has become possible.

IS 456-2000 has not proposed characteristic crackwidth. It is required to keep the probability of exceedence as small as possible. The importance of the structure, quality control in construction should be considered in selecting the value of probability of exceedence.

The characteristic value of a random variable following normal distribution is given by, $\mu+k^{*} \sigma$.

Where, $\mu$ is the mean value and $\sigma$ is the standard deviation. The factor $\mathrm{k}$ is suitably selected to represent the probability of exceedence or lowering.

\section{B. General Theory of Serviceability}

The structure to be designed on the basis of limit state should satisfy the following limit states:

a) Limit State of Collapse (Safety Requirement)

The following limit states of collapse are considered in design:

- Limit state of collapse in flexure

- Limit state of collapse in compression

- Limit state of collapse in shear

- Limit state of collapse in torsion

Dr. K. Manjunath, Professor, HOD, Department of Civil Engineering, MCE, Hassan.E-mail:kmnrpur@gmail.com

R. Meghana Bharadwaj, PG Student (CADS), MCE, Hassan. E-mail:mbharadwaj48@gmail.com

DOI:10.9756/BIJMMI.8180 


\section{b) Limit State of Serviceability}

The limit states of serviceability consists of:

- Excessive deflection

- Premature or excessive cracking

- Corrosion

- Excessive Vibration

Out of these, the important limit states of serviceability are excessive deflection and cracking. It is well known that in modern practice, structural failures are very common in terms of serviceability and are relatively rare in terms of safety. In particular it is the serviceability limit state of durability that calls for particular attention, indeed all over the world. The problem of inadequate durability is linked not only to such factors as improper making of concrete, attack from the environment and corrosion of reinforcement, but also to inadequate cover to the reinforcement, improper detailing and inadequate sizes for structural members, resulting in excessive deflections and crack widths.

\section{Serviceability Limit States: Crack-Width}

When we talk about structures, it is always the aesthetics and durability that matters the most. These things get influenced by the amount of cracks that are developed in the structure. One can always eliminate such cracks by using requisite number of small diameter bars which are well distributed in order to create ample amount of flexural reinforcing steel which controls the phenomenon of cracking. The number of bars can always be determined depending upon the minimum spacing requirements $\left(\mathrm{S}_{\mathrm{MIN}}\right)$. Thus, by creating an area of flexural steel by providing required number of bars will effectively control crack widths.

The allowable crack width in concrete depends on the environmental condition to which it is exposed.

Table 1: Classification of Structures According to Crack Width (IS 1343-1980)

\begin{tabular}{|l|l|}
\hline Type of concrete structure & Allowable crack width \\
\hline $\begin{array}{l}\text { Pre-stressed: Type 1 } \\
\text { (No tension in the section) }\end{array}$ & 0 \\
\hline $\begin{array}{l}\text { Pre-stressed: Type 2 } \\
\text { (No visible cracking) }\end{array}$ & 0 to $0.1 \mathrm{~mm}$ \\
\hline $\begin{array}{l}\text { Pre-stressed: Type 3 } \\
\text { Reinforced concrete normal design }\end{array}$ & $\begin{array}{l}0.1 \text { to } 0.2 \mathrm{~mm} \\
0.3 \mathrm{~mm}\end{array}$ \\
\hline
\end{tabular}

\section{RELIABILITY ANALYSIS}

\section{A. General}

Reliability is defined as the probability of given item performing its intended function for a given period of time which encounters certain operating conditions. Reliability goal can be expressed as, Resistance $\geq$ Action.

Here resistance is nothing but the load carrying capacity and the action may be the end results that include deflection, cracking, moments etc.,

The main aim of structural reliability analysis is to quantify the reliability of structures under the consideration of the uncertainties associated with the resistance and loads. The uncertainties that must be considered are the physical uncertainties, statistical uncertainties and the model uncertainties. The physical uncertainties include the loading environment, the material properties and the geometry of the structures. Statistical uncertainties may due to incomplete statistical information and the model uncertainties are due to the idealized mathematical description used to approximate the actual physical behavior of the structure.

\section{B. Monte Carlo Simulation Technique}

Without doing physical, real and actual experiment simply by knowing its probability distribution a set of random variable values can be created which is referred as simulation. A sample from a Monte Carlo simulation is similar to a sample of experimental observation; in the form of histograms these results of the simulation process can be presented. Main objective of Monte Carlo simulation is the generation of random numbers from prescribed probability distributions, for a given set of generated random numbers, the simulation process is deterministic. To generate normal variables Box Muller technique is used.

$$
\begin{aligned}
& \mathrm{u}_{1}=2 \ln \left(1 / \mathrm{v}_{1}\right)^{1 / 2} \cos \left(2 \pi \mathrm{v}_{1}\right) \\
& \mathrm{u}_{2}=2 \ln \left(1 / \mathrm{v}_{2}\right)^{1 / 2} \sin \left(2 \pi \mathrm{v}_{2}\right) \\
& \mathrm{y}_{1}=\mu+\sigma \mathrm{u}_{1} \\
& \mathrm{y}_{2}=\mu+\sigma \mathrm{u}_{2}
\end{aligned}
$$

Where,

$y_{1}$ and $y_{2}$ are the set of values for a set of random numbers $v_{1}$ and $v_{2} . \mu$ and $\sigma$ are the mean and standard deviation of corresponding variables under consideration.

\section{MATHEMATICAL FORMULATION}

The deterministic formulation is needed for the characterization of randomness in crack width in RC beams. The following articles describe the mathematical formulation as per the procedure suggested in IS 456-2000

\section{A. Introduction to T Beams}

$\mathrm{T}$ Beams are more commonly used in practice than the rectangular sections since the slab above the beam participates with the structural behavior of the beam. The slab which is in the compression side of the $\mathrm{T}$ beam is stressed laterally in compression. They resist the compression forces. The tension forces are taken up by the tension steel provided in the bottom web of the beam.

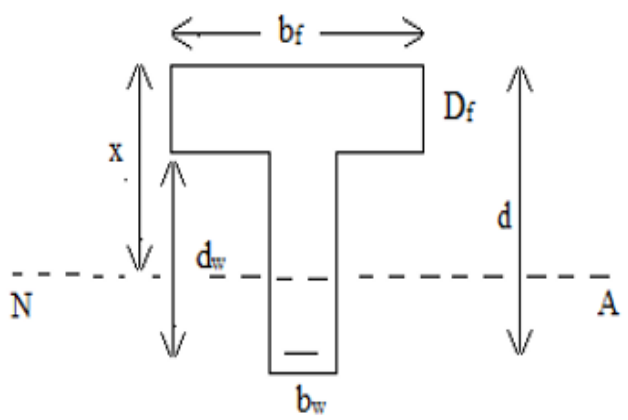

Figure 1: Cross-Section of a T Beam 
Only between the supports, the $\mathrm{T}$ beam acts as a flanged beam where positive bending moment prevails and the slab is under compression whereas over the supports, negative bending moment prevails and the slab is under tension and hence the beam acts as a rectangular beam.

\section{B. Procedure for the Calculation of Surface Crack Width of Singly Reinforced T Beam}

Maximum bending moment under service load is computed and the area of steel is calculated. Depth of neutral axis for cracked section is determined and then the moment of inertia of cracked section is calculated. By finding strain due to applied load at the level of steel and at the level of soffit $€ 1$, Surface crack width for a section under applied load as per IS 456-2000 is computed.

Where,

$$
\mathrm{Wcr}=\frac{3 * a c r * € m}{1+\frac{2 *(a c r-C \min )}{(D-x)}}
$$

$$
€ \mathrm{~m}=€ 1-\frac{(\mathrm{B} *(\mathrm{D}-\mathrm{x}) *(\mathrm{a}-\mathrm{x})}{3 * \mathrm{Es} * \operatorname{Ast} *(\mathrm{~d}-\mathrm{x})}
$$

$\mathrm{a}=$ Distance from compression edge to the point where crack width is calculated.acr $=$ Distance from the point considered to the nearest longitudinal bar.

Surface crack width for the above considered flange beam is calculated at 4 different locations.

Point A - Directly under the rebar

Point $\mathrm{B}$ - At the bottom corner

Point C - Mid way between two rebar

Point $\mathrm{D}-$ At $2 / 3^{\text {rd }}(\mathrm{d}-\mathrm{x})$ from the neutral axis

Table 2: Acr for Various Points under Consideration

\begin{tabular}{|l|l|}
\hline \multicolumn{1}{|c|}{ acr } & Points \\
\hline acr $=$ Cmin & A \\
\hline acr $=\left(\mathrm{Cmin}^{2}+C \operatorname{Cmin}^{2}\right)^{1 / 2}$ & B \\
\hline acr $=\left(\left(\frac{\text { spacing }}{2}\right)^{2}+C \operatorname{Cmin}^{2}\right)^{1 / 2}$ & C \\
\hline acr $=\left(\left(\frac{1}{3}(d-x)-\frac{d b}{2}\right)^{2}+C \min ^{2}\right)^{1 / 2}$ & D \\
\hline
\end{tabular}

\section{Basic Design Variables}

Table 3: Statistics of Basic Design Variables

\begin{tabular}{|l|l|l|l|l|}
\hline S.No & $\begin{array}{l}\text { Design } \\
\text { variable }\end{array}$ & $\begin{array}{l}\text { Mean value in } \\
\mathrm{mm}\end{array}$ & $\begin{array}{l}\text { Cov } \\
\%\end{array}$ & $\begin{array}{l}\text { Type of } \\
\text { distribution }\end{array}$ \\
\hline 1 & D & $300-650$ & 5 & Normal \\
\hline 2 & d & $250-600$ & 5 & Normal \\
\hline 3 & bf & $1813.33-2146.67$ & 3 & Normal \\
\hline 4 & bw & 230 & 3 & Normal \\
\hline 5 & df & 125 & 5 & Normal \\
\hline 6 & fy & 415 & 10 & Normal \\
\hline 7 & fck & 20 & 15 & Normal \\
\hline 8 & cl & 50 & 10 & Normal \\
\hline 9 & Ast & As per design & 5 & Normal \\
\hline 10 & Asc & As per design & 5 & Normal \\
\hline
\end{tabular}

Case 1: Neutral Axis Lying within Flange $(x<D f)$

For analyzing characterization of randomness in limit state of cracking for a RC T beam, a beam of effective flange width bf $=1630 \mathrm{~mm}$, breadth of web $=200 \mathrm{~mm}$, depth of flange $\mathrm{Df}=$ $100 \mathrm{~mm}$, total depth $\mathrm{D}=350 \mathrm{~mm}$, having a span of $5 \mathrm{~m}$ with effective cover of $30 \mathrm{~mm}$ is considered. Compression strength of concrete fck $=20 \mathrm{~N} / \mathrm{mm}^{2}$, Yield strength of steel fy $=$ $415 \mathrm{~N} / \mathrm{mm}^{2}$ is used.

Table 4: Characteristic Crack Width at Point A

\begin{tabular}{|l|l|l|l|l|l|}
\hline $\begin{array}{l}\text { SL } \\
\text { no }\end{array}$ & $\begin{array}{l}\text { Service } \\
\text { load } \\
\mathrm{KN} / \mathrm{m}\end{array}$ & $\begin{array}{l}\text { Mean } \\
\mu\end{array}$ & $\begin{array}{l}\text { Standard } \\
\text { deviation } \\
\sigma\end{array}$ & $\begin{array}{l}\text { COV } \\
\text { in } \%\end{array}$ & $\begin{array}{l}\text { Characteristic } \\
\text { crack width } \\
\mathrm{W}_{\mathrm{ch}}=\mu+1.645 \sigma\end{array}$ \\
\hline 1 & 26 & 0.108 & 0.0101 & 9.34 & $0.125 \mathrm{~mm}$ \\
\hline 2 & 28 & 0.121 & 0.0109 & 8.43 & $0.1376 \mathrm{~mm}$ \\
\hline 3 & 30 & 0.134 & 0.0105 & 7.884 & $0.1508 \mathrm{~mm}$ \\
\hline 4 & 32 & 0.146 & 0.0111 & 7.62 & $0.164 \mathrm{~mm}$ \\
\hline
\end{tabular}

Table 5: Characteristic Crack Width at Point B

\begin{tabular}{|l|l|l|l|l|l|}
\hline $\begin{array}{l}\text { SL } \\
\text { no }\end{array}$ & $\begin{array}{l}\text { Service } \\
\text { load } \\
\mathrm{KN} / \mathrm{m}\end{array}$ & $\begin{array}{l}\mu \text { Mean } \\
\mu\end{array}$ & $\begin{array}{l}\text { Standard } \\
\text { deviation } \\
\sigma\end{array}$ & $\begin{array}{l}\text { COV } \\
\text { in } \%\end{array}$ & $\begin{array}{l}\text { Characteristic } \\
\text { crack width } \\
\mathrm{W}_{\text {ch }}=\mu+1.645 \sigma\end{array}$ \\
\hline 1 & 26 & 0.144 & 0.0142 & 9.85 & $0.167 \mathrm{~mm}$ \\
\hline 2 & 28 & 0.162 & 0.0146 & 9.04 & $0.186 \mathrm{~mm}$ \\
\hline 3 & 30 & 0.177 & 0.0152 & 8.602 & $0.202 \mathrm{~mm}$ \\
\hline 4 & 32 & 0.194 & 0.016 & 8.21 & $0.221 \mathrm{~mm}$ \\
\hline
\end{tabular}

Table 6: Characteristic Crack Width at Point $\mathrm{C}$

\begin{tabular}{|l|l|l|l|l|l|}
\hline $\begin{array}{l}\text { SL } \\
\text { no }\end{array}$ & $\begin{array}{l}\text { Service } \\
\text { load } \\
\mathrm{KN} / \mathrm{m}\end{array}$ & $\begin{array}{l}\text { Mean } \\
\mu\end{array}$ & $\begin{array}{l}\text { Standard } \\
\text { deviation } \\
\sigma\end{array}$ & $\begin{array}{l}\text { COV } \\
\text { in } \%\end{array}$ & $\begin{array}{l}\text { Characteristic } \\
\text { crack width } \\
\mathrm{W}_{\mathrm{ch}}=\mu+1.645 \sigma\end{array}$ \\
\hline 1 & 26 & 0.177 & 0.0302 & 17.04 & $0.2272 \mathrm{~mm}$ \\
\hline 2 & 28 & 0.198 & 0.033 & 16.78 & $0.252 \mathrm{~mm}$ \\
\hline 3 & 30 & 0.219 & 0.036 & 16.70 & $0.280 \mathrm{~mm}$ \\
\hline 4 & 32 & 0.239 & 0.0373 & 15.64 & $0.3004 \mathrm{~mm}$ \\
\hline
\end{tabular}

Table 7: Characteristic Crack Width at Point D

\begin{tabular}{|l|l|l|l|l|l|}
\hline $\begin{array}{l}\text { SL } \\
\text { no }\end{array}$ & $\begin{array}{l}\text { Service } \\
\text { load } \\
\mathrm{KN} / \mathrm{m}\end{array}$ & $\begin{array}{l}\text { Mean } \\
\mu\end{array}$ & $\begin{array}{l}\text { Standard } \\
\text { deviation } \\
\sigma\end{array}$ & $\begin{array}{l}\text { COV } \\
\text { in \% }\end{array}$ & $\begin{array}{l}\text { Characteristic } \\
\text { crack width } \\
\mathrm{W}_{\mathrm{ch}}=\mu+1.645 \sigma\end{array}$ \\
\hline 1 & 26 & 0.158 & 0.027 & 17.58 & $0.204 \mathrm{~mm}$ \\
\hline 2 & 28 & 0.177 & 0.030 & 17.10 & $0.227 \mathrm{~mm}$ \\
\hline 3 & 30 & 0.194 & 0.032 & 16.51 & $0.246 \mathrm{~mm}$ \\
\hline 4 & 32 & 0.212 & 0.034 & 16.17 & $0.269 \mathrm{~mm}$ \\
\hline
\end{tabular}

D. Histogram and Probability Distribution Diagrams for Surface Crack Width of Singly Reinforced Beam

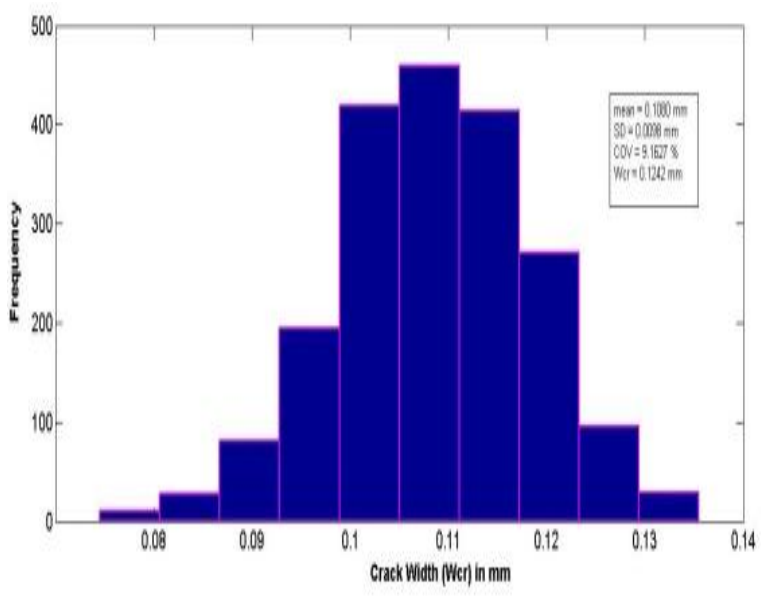

Figure 1 


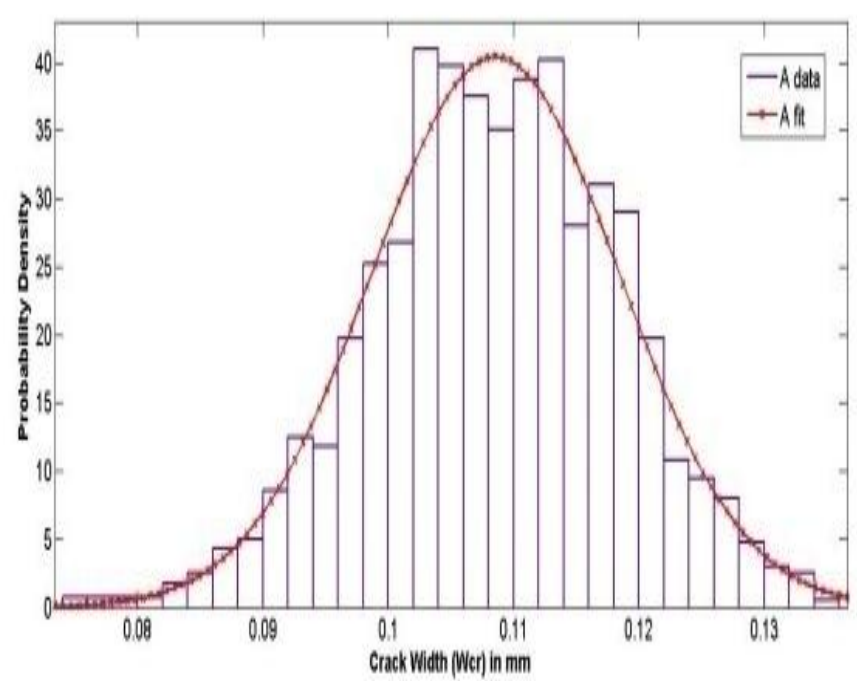

Figure 2: Histogram and Probability Distribution Curve for Load 26kN/m under Point A
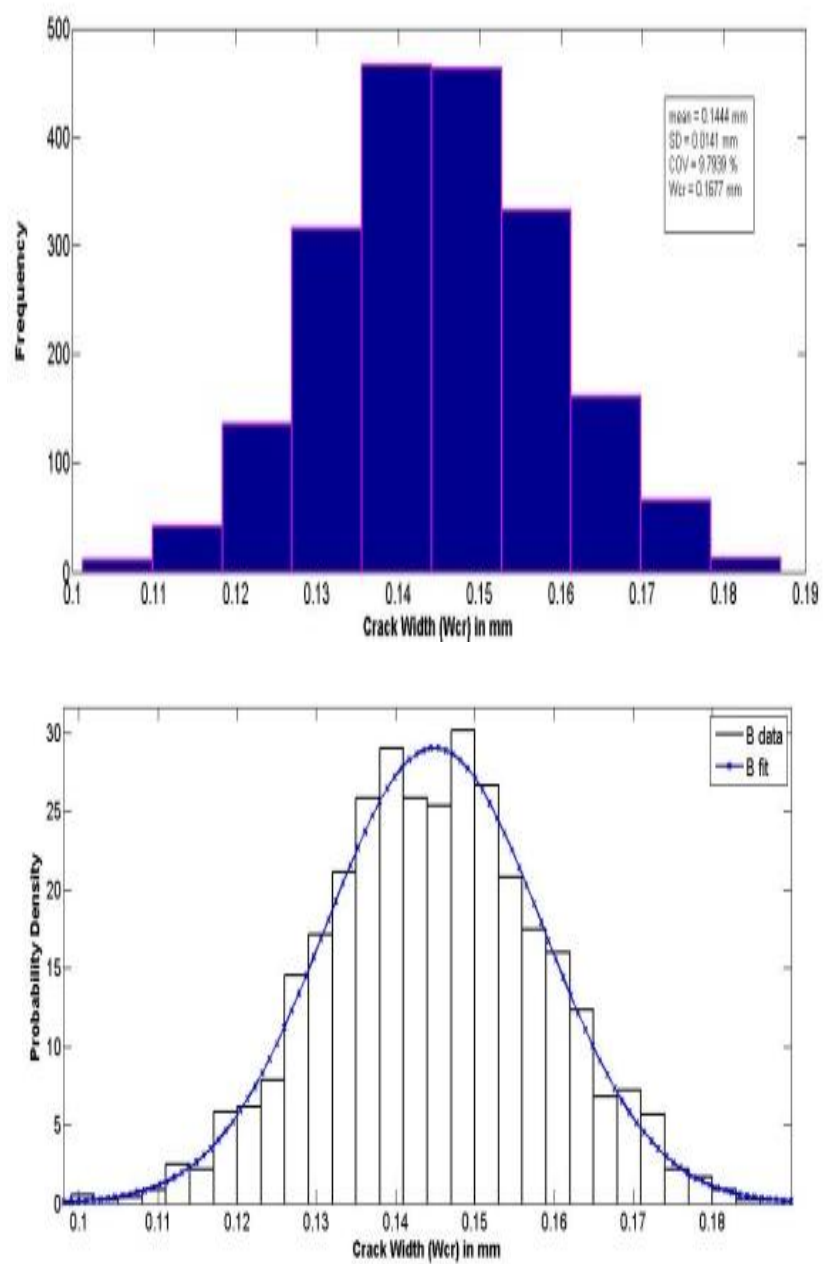

Figure 3: Histogram and Probability Distribution Curve for Load $26 \mathrm{kN} / \mathrm{m}$ under Point B
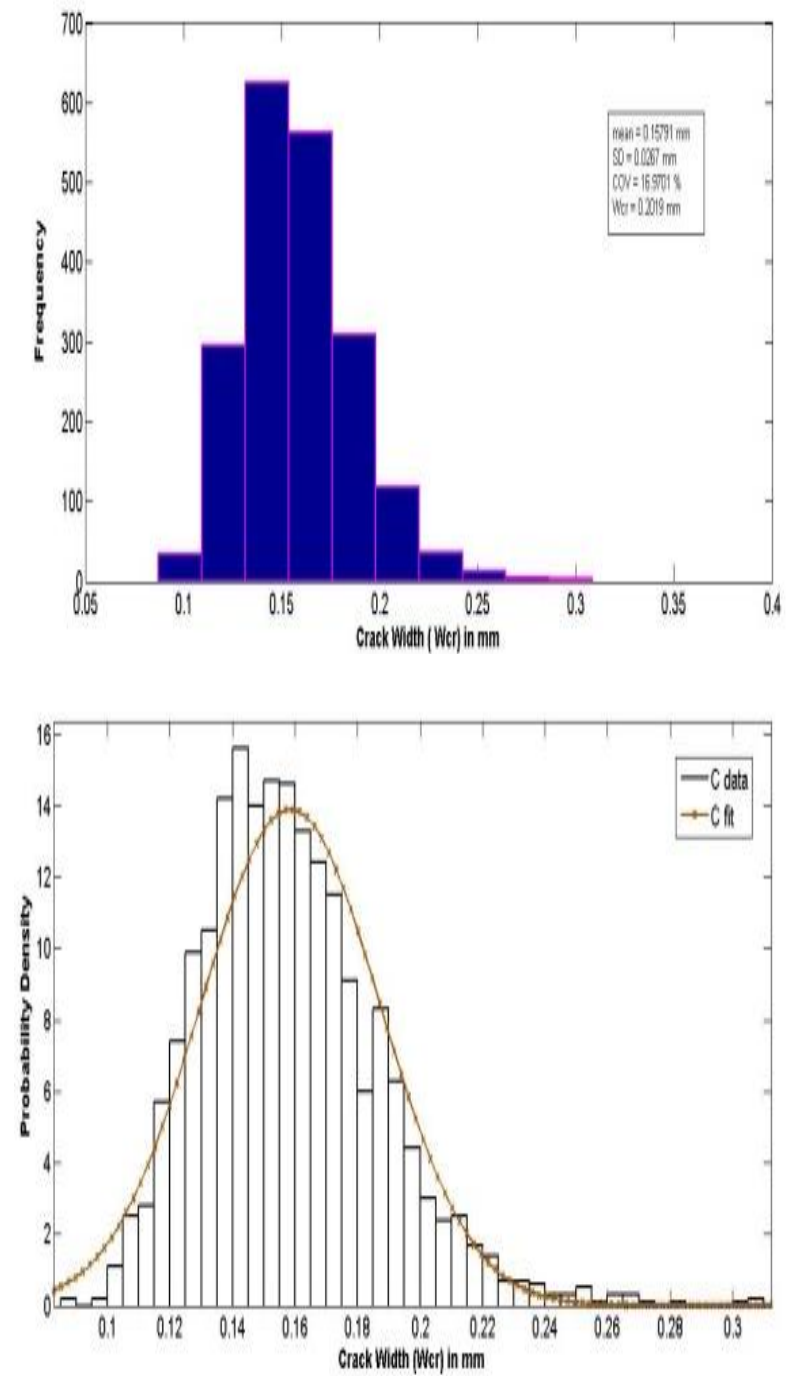

Figure 4: Histogram and Probability Distribution Curve for Load 26kN/m under Point C

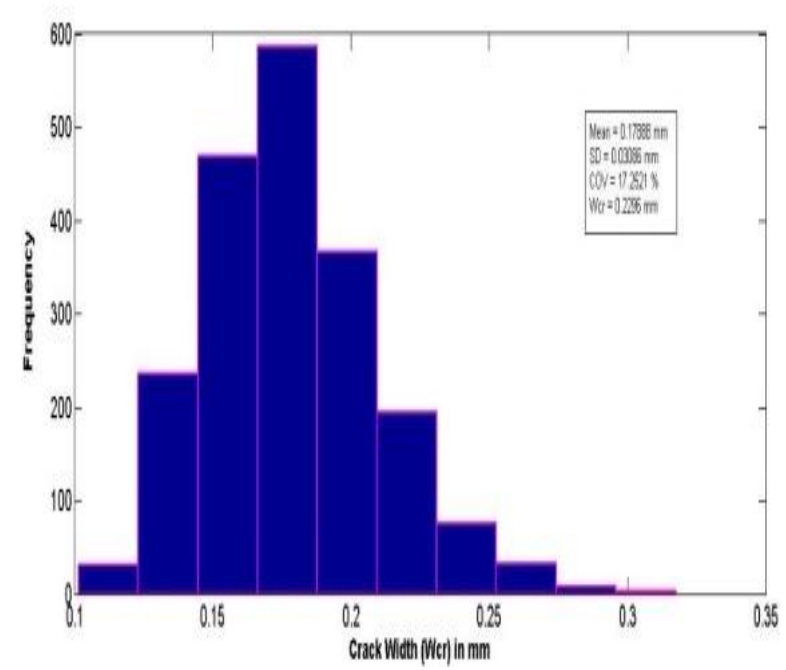




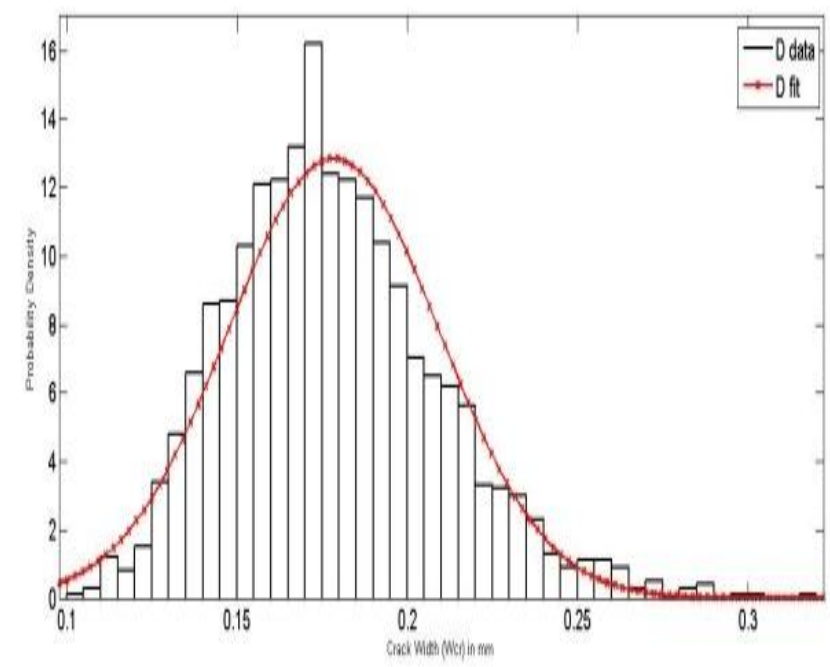

Figure 5: Histogram and Probability Distribution Curve for Load $26 \mathrm{kN} / \mathrm{m}$ under Point D

\section{E. Matlab}

It is a high-performance language for technical computing. It integrates computation, visualization, and programming in an easy-to-use environment where problems and solutions are expressed in familiar mathematical notations.

Matlab program has been developed for singly reinforced and doubly reinforced beams under different locations of neutral axis for the determination of surface crack width. K-S test is used to check the goodness- of- fit.

\section{CONCLUSION}

The randomness in surface crack width is characterized by the normal distribution and the characteristic crack width is derived as that value which has a probability of exceedence of $5 \%$, for $\mathrm{RC} \mathrm{T}$ beams. This will help in developing the durability based design concept of RC members.

\section{REFERENCES}

[1] R. Ranganathan, "Reliabilty Analysis and design of structures", Tata McGraw-Hill Publication Company Limited, New Delhi, 1990.

[2] IS 456-2000, Indian Standard code of practice for Plain and Reinforced Concrete

[3] SP 16:2000, Design Aids for reinforced concrete, Bureau of Indian Standard, New Delhi.

[4] B.C. Punmia, A.K. Jain and A.K. Jain, "Limit state design of reinforced concrete", Firewall Media, 2007. 